\title{
Peran Humas Kota Padang dalam Mensosialisasikan Smart City di Kota Padang
}

\author{
Ridho Darman $^{a}$ \\ a Jurusan Sistem Informasi Fakultas Teknologi Informasi Universitas Andalas, Limau Manis, Padang, 25163, Indonesia
}

\section{INFORMASI ARTIKEL}

\section{Sejarah Artikel:}

Diterima Redaksi: 00 Februari 00

Revisi Akhir: 00 Maret 00

Diterbitkan Online: 00 April 00

\section{KATA KUNCI}

Smart City, Padang, Humas

KORESPONDENSI

\section{A B S T R A K}

Konsep smart city kini tengah marak digalakkan di berbagai negara, termasuk Indonesia. Penerapannya pun dinilai sangat bermanfaat bagi kehidupan masyarakat. Kota Padang merupakan pusat pendidikan di Provinsi Sumatra Barat, dimana pendidikan merupakan salah satu faktor terpenting di dalam mewujudkan smart city. Kajian ini bertujuan untuk mengetahui sejauh mana peran Humas Kota Padang dalam mensosialisasikan smart city di Kota Padang. .

Telepon: $+628 * * * * * * * * * *$

E-mail: 1511522004@student.unand.ac.id

\section{PENDAHULUAN}

Kota Padang adalah kota terbesar di pantai barat Pulau Sumatra sekaligus ibu kota dari Provinsi Sumatra Barat, Indonesia. Kota Padang sejak dari zaman kolonial Belanda telah menjadi pusat pendidikan di Sumatra Barat. Pada tahun 1864, jumlah pelajar yang terdaftar di sekolah yang ada di kota ini sebanyak 237 orang [1]. Smart City adalah penggunaan teknologi komputasi cerdas untuk mengintegrasikan komponen-komponen penting dari infrastruktur dan layanan kota, seperti administrasi kota, pendidikan, kesehatan, keselamatan publik, real estate, transportasi dan keperluan kota lainnya, dimana penggunaan keseluruhannya harus dilakukan secara cerdas, saling berhubungan dan efisien [2].

Pada hakikatnya, ketersediaan serta kualitas infrastruktur Teknologi Informasi dan Komunikasi (TIK) bukan satu-satunya karakteristik smart city. Selain TIK, yang lebih penting adalah peran manusia (smart people) dan pendidikan dalam pembangunan perkotaan. Smart people adalah mereka yang memiliki kemauan belajar, bersikap plural secara sosial dan etnis, fleksibel, kreatif, berpikiran terbuka, dan selalu terlibat dan berpartisipasi dalam kegiatan kemasyarakatan. Sebagai warga negara, smart people sebetulnya merupakan subjek terpenting dari smart city, namun terabaikan. Keberhasilan membangun smart city tidak saja dinilai dari kesuksesan dalam memanfaatkan TIK untuk pembangunan infrastruktur, tetapi bagaimana teknologi tersebut bermanfaat sebanyak-banyaknya untuk kepentingan publik [3-5].

Humas dalam lembaga pemerintahan merupakan suatu keharusan fungsional dalam rangka penyebaran informasi, kebijakan, program dan kegiatan- kegiatan pemerintah kepada masyarakat. Terutama di Indonesia lembaga kehumasan sangat diperlukan. Humas merupakan kelanjutan dari proses penetapan kebijakan pemerintah, memberi layanan informasi kepada masyarakat, sehingga humas dapat memperoleh kepercayaan dari publiknya, yaitu masyarakat [6]. Humas yang dapat berperan sebagai penghubung antara organisasi pemerintahan dengan publiknya [7]. Pada kajian ini membahas mengenai pngaruh Humas Pemerintah Kota Padang dalam mensosialisasikan konsep smart city di Kota Padang, mengingat Kota Padang merupakan pusat pendidikan di Sumatra Barat yang merupakan salah satu unsur terpenting dalam mewujudkan smart city.

\section{TINJAUAN PUSTAKA}

\subsection{Smart City}

Smart city atau kota pintar banyak diterapkan di berbagai kota pada negara maju sejak awal perkembangan teknologi 
komunikasi dan informasi. Smart city mengarah pada sebuah konsep bahwa kota yang dapat memahami keadaan emosi dan perilaku masyarakat terhadap kepuasan layanan publik, menambah kepercayaan dan rasa aman terhadap pemerintah, meningkatkan kualitas dan taraf hidup, memanfaatkan layanan teknologi sebagai media interaktif antara masyarakat dan pemerintah, serta mengintegrasikan berbagai komponen pemerintahan dengan respon yang cepat tanggap terhadap aspirasi apapun yang datang dari masyarakat. Tujuan dari membangun konsep smart city untuk menciptakan good governance dan menumbuhkan kepuasan masyarakat terhadap layanan pemerintahan. Smart City didefinisikan sebagai kota yang mampu menggunakan SDM, modal sosial, dan infrastruktur telekomunikasi modern untuk mewujudkan pertumbuhan ekonomi berkelanjutan dan kualitas kehidupan yang tinggi dengan manajemen sumber daya yang bijaksana melalui pemerintahan berbasis partisipasi masyarakat [8]. Beberapa daerah yang telah melaksanakan program ini di antaranya Surabaya, Tanggerang, Bandung, Bekasi dan lain-lain [9].

\subsection{Humas}

Humas atau hubungan masyarakat adalah fungsi manajemen yang membangun dan mempertahankan hubungan yang baik dan bermanfaat antara organisasi dengan publik yang memengaruhi kesuksesan atau kegagalan organisasi tersebut. Humas ialah pihak yang akan membangun dan mempertahankan hubungan baik antara organisasi dengan publik, sebagai pihak yang berpengaruh untuk kelangsungan organisasi tersebut. Sebuah lembaga sangat membutuhkan bantuan serta dukungan humas dalam menjalankan aktivitasnya demi keberlangsungan organisasi untuk tetap dapat bertahan dan memperoleh dukungan publik. Untuk memperoleh dukungan publik, semua organisasi yang termasuk dalam kategori Badan Publik seperti Pemerintahan, dalam menjalankan tugas dan fungsinya dituntut untuk bisa menerapkan tata kelola yang baik. Dalam mencapai tata kelola yang baik, perlu ditetapkannya prinsip-prinsip akuntabilitas, transparansi dan partisipasi masyarakat dalam setiap proses penetapan kebijakan publik [6].

\subsubsection{Humas Kota Padang}

Menurut Peraturan Walikota Padang Nomor 63 Tahun 2016 Tentang Kedudukan, Susunan Organisasi, Tugas, Fungsi, dan Tata Kerja Sekretariat Daerah, asisten administrasi Kota Padang membawahi bagian humas yang terdiri dari (a) sub bagian publikasi, (b) sub bagian dokumentasi dan koordinasi kehumasan, (c) sub bagian pelayanan informasi publik. Bagian Humas dipimpin oleh seorang Kepala Bagian yang dalam melaksanakan tugasnya berada di bawah dan bertanggungjawab kepada Sekretaris Daerah melalui Asisten Administrasi [10].

\subsubsection{Tugas Pokok dan Fungsi Humas Kota Padang}

Menurut Peraturan Walikota Padang Nomor 63 Tahun 2016 Tentang Kedudukan, Susunan Organisasi, Tugas, Fungsi, dan Tata Kerja Sekretariat Daerah, dalam menyelenggarakan tugas pokoknya, bagian Humas mempunyai fungsi [10]:

a. Menyusun rencana kerja, evaluasi, dan laporan di bidang humas Pemerintah Kota Padang.

b. Membentuk, meningkatkan, dan memelihara citra dan reputasi positif pemerintah kota dengan menyediakan infrastruktur tentang kebijakan, program, dan kegiatan instansi.

c. Menciptakan iklim hubungan internal dan eksternal pemerintah kota secara kondusif dan dinamis.

d. Menjadi penghubung antara pemerintah kota dengan publik;

e. Membina hubungan kerjasama dan kemitraan dengan media massa.

f. Melaksanakan koordinasi penyiaran pemerintah kota dengan media elektronik pemerintah dan swasta.

g. Melaksanakan pemberdayaan humas pemerintah, swasta, dan kelompok informasi masyarakat.

h. Melaksanakan tugas kedinasan lain yang diberikan oleh atasan sesuai dengan tugas dan fungsinya.

\section{METODOLOGI}

Metodologi pada penelitian ini menggunakan pendekatan kualitatif dan analisis data. Sumber data primer diperoleh dari hasil studi literatur. Analisis data yang digunakan juga berasal dari hasil survei berupa kuisoner online.

\section{HASIL DAN PEMBAHASAN}

Memasuki era penerapan TIK dan progres Kota Padang menjadi smart city, Humas perlu untuk melakukan adaptasi dengan melaksanakan peran-perannya dengan mengkombinasikan penerapan TIK. Banyak media atau tools yang dapat digunakan oleh Humas Pemerintah Kota Padang dalam menjalanan kinerjanya. Salah satunya adalah smartphone atau personal computer yang saat ini menjadi sesuatu yang penting dan sangat membantu pekerjaan manusia, khususnya dalam hal komunikasi dan interaksi [7]. Berdasarkan pengamatan penulis, TIK telah merubah cara komunikasi dan interaksi public seperti masyarakat.

Hubungan face to face menjadi berkurang dengan adanya gadget, namun efisiensi dan manfaat lain yang didapat diantara humas bisa dengan cepat memberikan informasi ataupun menerima informasi. Perkembangan TIK yang sangat pesat akan berpengaruh dalam kegiatan pemerintahan. Pendapat dari para ahli yang mengatakan bahwa negara dapat berkembang jika menguasai informasi yang merupakan bagian dari TIK. Tuntutan penggunaan TIK dalam bidang kehumasan, khususnya Humas Pemerintahan juga datang karena model Public Relations. Pada model Grunig dan Hunt, praktik kehumasan pemerintahan terletak pada model public information yang bertujuan untuk menyebarkan informasi. Model ini paling banyak digunakan dalam praktik kehumasan dengan presentase sebesar 50\%. Peran humas sangat penting terutama dalam penyebaran informasi. Dengan eksistensi dari Humas khususnya Humas Pemerintahan, informasi dapat sampai kepada publik dengan presentase sebesar $50 \%$ dan menjadi model paling dominan digunakan. Oleh karena itu, fungsi dominan dari humas adalah menyediakan informasi yang dibutuhkan publik [7] [11]. Dalam penyebaran informasi humas Kota Padang telah memanfaatkan sosial media salah satunya facebook yang telah di like sebanyak 109.341 dan diikuti sebanyak 109.865 pengguna akun facebook seperti Gambar 1 . 


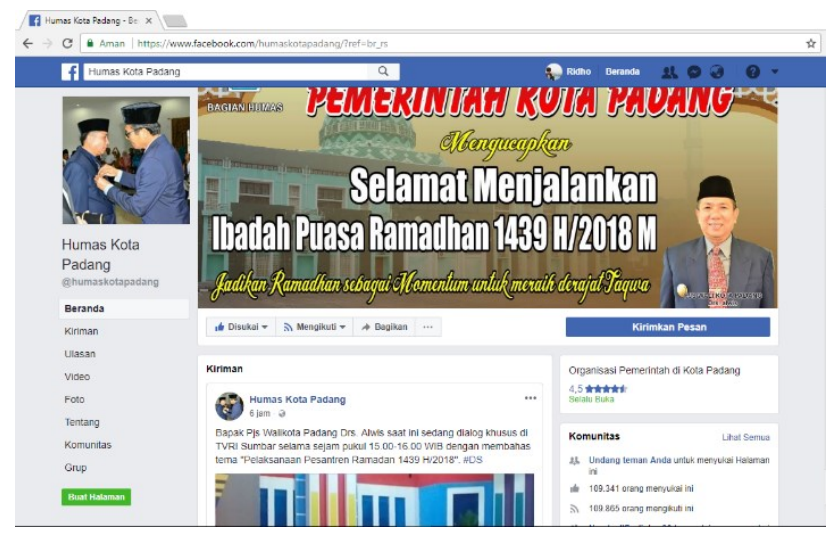

Gambar 1. Facebook Humas Kota Padang

Setiap post dari facebook Humas Kota Padang ratarata mencapai 5-20 like. Selama tahun 2018 sudah terdapat 2 post yang berkaitan tentang smart city. Pemerintah Kota Padang juga memiliki website yang beralamat www.padang.go.id seperti Gambar 2.

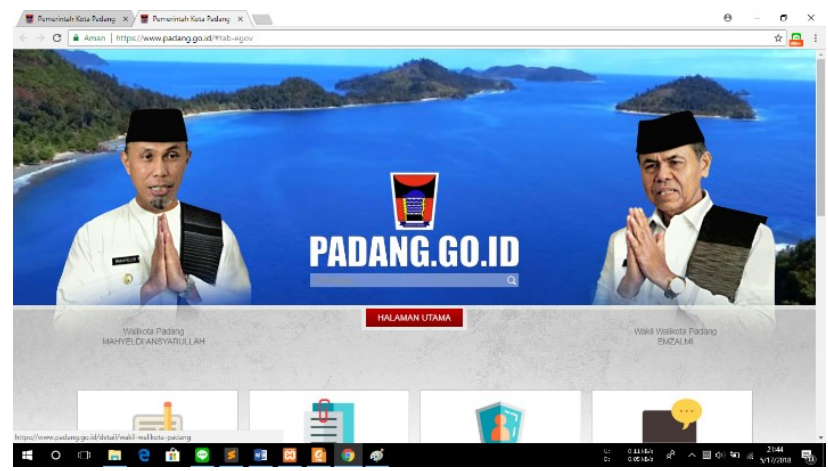

Gambar 2. Website Pemerintah Kota Padang

Di dalam website tersebut terdapat menu E-government yang terdiri dari 17 sub menu seperti Gambar 3.

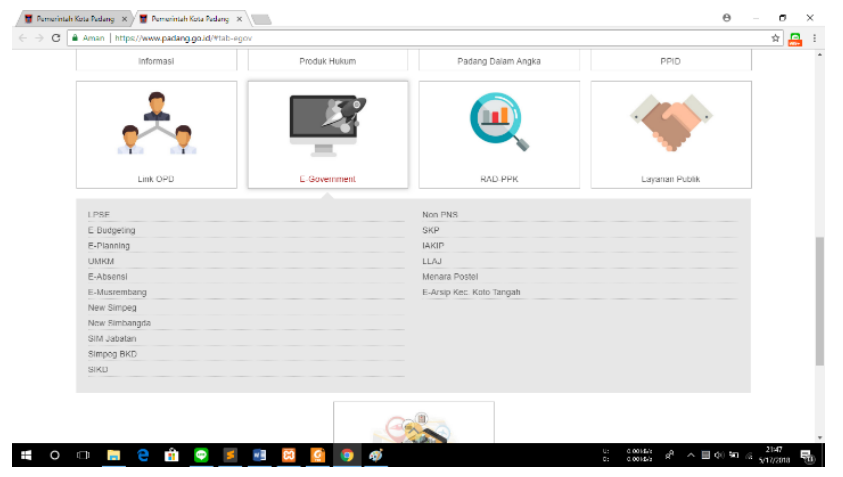

Gambar 3. Sub Menu E-Government Website Kota Padang

Untuk mendukung smart tourism sebagai salah satu komponen dari smart city Pemerintah Kota Padang juga mempromosikan aplikasi mobile yang bernama "Padang dalam Genggaman" yang dapat diunduh di play store seperti Gambar 4 .

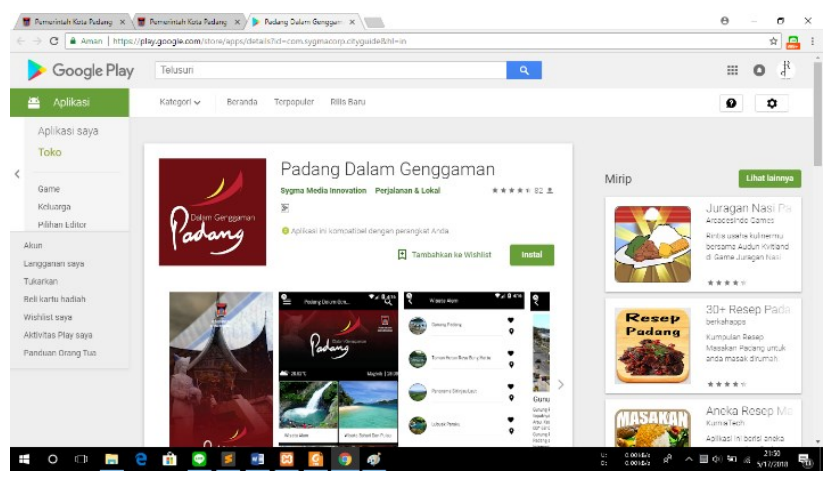

Gambar 4. Aplikasi Mobile Padang dalam Genggaman

Untuk mengetahui peran Humas Kota Padang dalam Mensosialisasikan smart city di Kota Padang dilakukan survei dengan pengambilan sampel secara acak melalui kuisoner online, berikut hasil kuisoner yan terisi dari 49 responden

a. Pengetahuan masyarakat Kota Padang terhadap smart city dapat dilihat pada Gambar 5 . 49 tanggapan

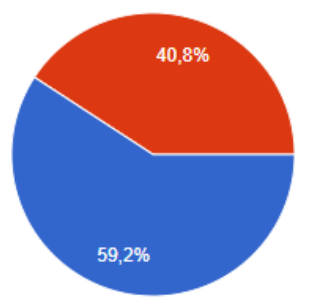

Tahu - Tidak Tahu

Gambar 5. Pengetahuan masyarakat Kota Padang terhadap smart city

b. Pengetahuan masyarakat Kota Padang terhadap smart city berdasarkan pekerjaan dapat dilihat pada Gambar 6 .

Apakah anda tahu apa itu smart city?

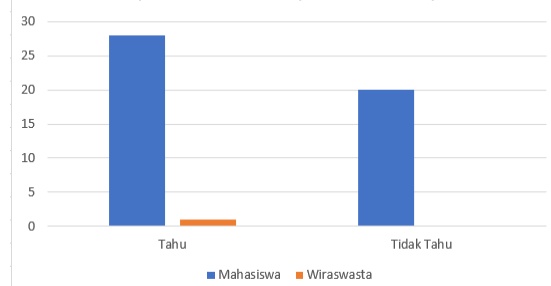

Gambar 6. Pengetahuan masyarakat Kota Padang terhadap smart city berdasarkan pekerjaan

c. Pengetahuan masyarakat Kota Padang terhadap smart city berdasarkan kelompok umur dapat dilihat pada Gambar 7.

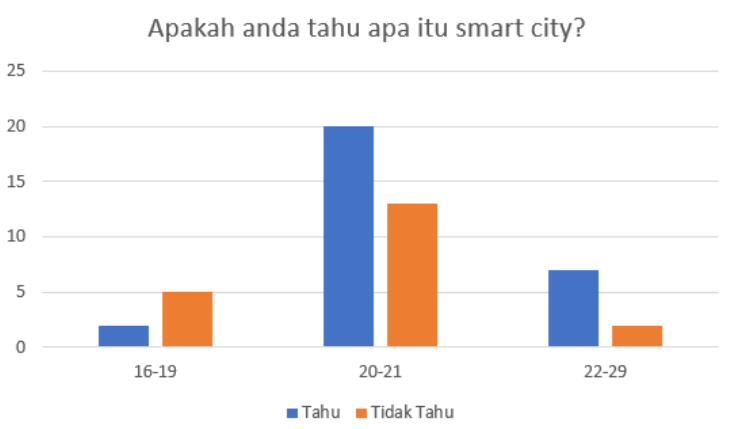

Gambar 7. Pengetahuan masyarakat Kota Padang terhadap smart city berdasarkan kelompok umur 
d. Pengetahuan masyarakat Kota Padang terhadap smart city berdasarkan tempat tinggal dapat dilihat pada Gambar 8 .

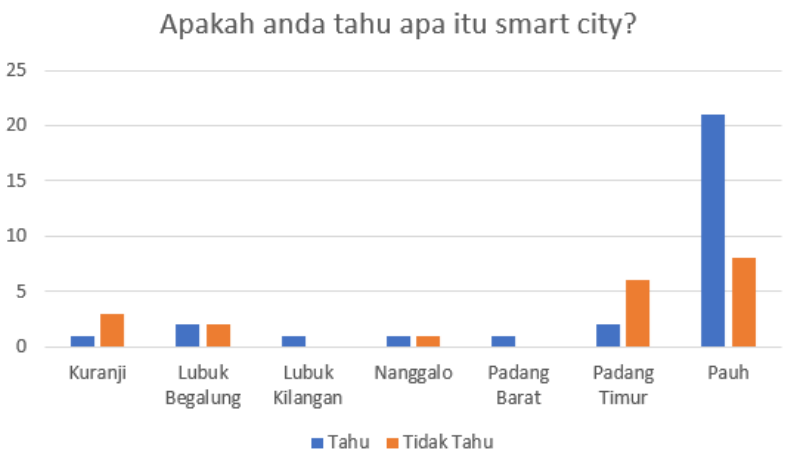

Gambar 8. Pengetahuan masyarakat Kota Padang terhadap smart city berdasarkan tempat tinggal

e. Sumber pengetahuan masyarakat Kota Padang terhadap smart city dapat dilihat pada Gambar 9.

Darimana anda mengetahui smart city?

29 tanggapan

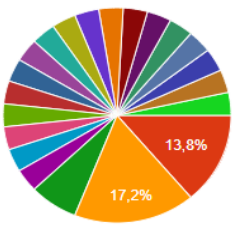

- Facebook Humas Kota Padang

- Website Resm

Tidak tau

- Buku

p perkuliahan

- Instagra

$\Delta 1 / 3 \boldsymbol{\nabla}$

Gambar 9. Sumber pengetahuan masyarakat Kota Padang terhadap smart city

\section{KESIMPULAN DAN SARAN}

\subsection{Kesimpulan}

Kesimpulan yang dapat ditarik dari penelitian ini yaitu:

1. Humas Kota Padang telah berupaya mensosialisasikan smart city menggunakan sosial media yang banyak digunakan masyarakat, yakni facebook dan juga melalui website resmi Pemko Padang

2. Humas Kota Padang belum terlalu berpengaruh mensosialisasikan smart city dikalangan pelajar/mahasiswa, karena lebih dari $40 \%$ pelajar/mahasiswa yang tidak mengetahui smart city, padahal pendidikan adalah salah satu komponen utama dalam mewujudkan smart city.

3. Smart city lebih banyak diketahui oleh masyarakat Kota Padang yang berusia diatas 20 tahun, sedangkan yang berusia dibawah 20 tahun kebanyakan tidak mengetahui.

4. Berdasarkan hasil survei, Kecamatan Pauh adalah masyarakat yang paling banyak mengetahui tentang smart city

5. Internet merupakan sumber utama pengetahuan masyarakat Kota Padang terhadap smart city.

\subsection{Saran}

Untuk kajian lebih lanjut diharapkan menggunakan sampel data survei yang lebih banyak dengan tambahan pertanyaan kuisoner yang lebih detail.

\section{UCAPAN TERIMA KASIH}

Terima kasih kepada Bapak Hasdi Putra, M.T. selaku dosen pengampu Mata Kuliah E-Goverment yang telah memberikan arahan terhadap jalannya pelaksanaan tugas kuliah ini.

\section{DAFTAR PUSTAKA}

[1] E. E. Graves, Asal-Usul Elite Minangkabau Modern: Respons Terhadap Kolonial Belanda Abad XIX/XX, Yayasan Obor Indonesia, 2007.

[2] D. Washburn, U. Sindhu, S. Balaouras, R. A. Dines, N. M. Hayes dan L. E. Nelson, "Helping CIOs Understand "Smart City" Initiatives," Cambridge, 2010 Februari 11. [Online]. Available:http://public.dhe.ibm.com/partnerworld/pub/smb/smarterplanet/ [Diakses 2018 April 24].

[3] I. M. Sadjati, "Smart Education dan Smart City," Universitas Terbuka, 2017. [Online]. Available: http://repository.ut.ac.id/7070/1/UTFMIPA2017-01-ida.pdf. [Diakses 24 April 2018].

[4] Nam, T. dan Pardo, T. A., "Conceptualizing smart city with dimensions of technology,people, and institutions," dalam The Proceedings of the 12th Annual International Conference on Digital Government, New York, 2011.

[5] Dameri, R. P., "Searching for smart city definition: a comprehensive proposal," International Journal of Computers \& Technology, vol. 11, no. 5, pp. 2544-2551, 2013.

[6] N. S. Zarni, "Peran Dan Fungsi Humas Pemerintah Kota Padang dalam Upaya Mengimplementasikan Kebijakan Pemerintah Kota Padang (Studi Deskriptif Penertiban Kawasan Wisata Pantai Padang Tahun 2016)," Universitas Andalas, Padang, 2016.

[7] T. Ristanto, "Peran Humas Pemerintas Kota Balikpapan dalam Mengimplementasikan Konsep Smart City di Kota Balikpapan," Commonline Departemen Komunikasi, vol. 4, no. 1, pp. 387-399, 2017.

[8] A. Caragliu, "Smart Cities in Europe. In 3 rd Central European ConferenceInRegionalSaence-CERS," 2009. [Online]. Available: http://www.cers.tuke.sk/cers\%202009/PDF/01-03.pdf.

[9] N. Made Ambarani Sumerta Putri, N. Nyoman Dewi Pascarani dan I. Dewa Ayu Sugiarica, "Peran Humas Pemerintah Kota Denpasar," Jurnal Medium, vol. 1, no. 1, pp. 1-9, 2017.

[10] Peraturan Walikota Padang Nomor 63 Tahun 2016 Tentang Kedudukan, Susunan Organisasi, Tugas, Fungsi, dan Tata Kerja Sekretariat Daerah.

[11] Wilcox dan Cameron, Dasar-dasar Public Relations, Bandung: PT RemajaRosda Karya, 2006. 